\title{
The Concept of Damage Control Laparotomy
}

\author{
Qamaruddin Baloch ${ }^{1, *}$, Sarah Arif ${ }^{2}$, Farhan Zaheer ${ }^{1}$ and Imrana Aziz ${ }^{1}$ \\ ${ }^{1}$ Department Surgical Unit I, Dow University of Health Sciences and Civil Hospital, Karachi, Pakistan. \\ ${ }^{2}$ F-10, Safari Boulevard, Phase I, Block 15, Gulistan-e-jauhar, Karachi, Pakistan.
}

\begin{abstract}
Over the past 25 years, principles of damage control Laparotomy have saved many lives. Quick recognition of injuries and immediate transfer to operating room are essential. Patients with polytrauma have substantial haemorrhage and go into a vicious cycle of death (hypothermia, coaugulopathy and acidosis). Prior to surgery, adequate resuscitation helps to improve both intra and post-operative mortality. And the focus is on control of bowel contamination and haemorrhage. Once achieved, patient is resuscitated in ICU setup to optimize physiology. Adequate hydration, blood transfusion, re-warming of the patient and other supportive measures are taken to arrest the ongoing cycle of coagulation, hypothermia and metabolic acidosis. Later, patient is moved to theatre for definitive management of injuries. Improvement in patient outcome has been reported by an increased understanding of damage control and the anatomical and physiological steps taken to improve the outcomes.
\end{abstract}

Keywords: Adequate hydration, Damage control, Hypothermia, Hypothermia and metabolic acidosis, Laparotomy.

doi.org/10.21089/njhs.22.0075

\section{INTRODUCTION}

The term 'Damage Control' is not new to the field of trauma. Since the 1950s, the Navy and Maritime industry has used this term which is defined as 'the capacity of a ship to absorb damage and maintain mission integrity'[1]. The concept behind damage control surgery is to limit the surgical procedure towards the control of ongoing blood loss, contamination and decrease the procedure time. This allows the patient to regain his/her optimum physiological state after which definitive surgical repair may be done [2]. This has significantly increased survival in critically injured patients reducing mortality rates to $50 \%$ [3]. In 1983, Dr Harlan Stone suggested that if patients were found to have coagulopathy then their procedures should be shortened. Damage Control in trauma surgery was described by Rotundo as a three-phase technique to limit damage in a trauma patient. A 'pretheatre' phase was later described by Johnson and Schwab [4].

Patients having multiple injuries usually present with massive haemorrhage and a vicious cycle of death (hypothermia, coagulopathy and acidosis). During damage control, a surgeon not only controls bleeding by packing or applying clamps but also limits intestinal contamination. Next, the patient is shifted to ICU for resuscitation where his/her phys-

*Address correspondence to this author at Department Surgical Unit I, Dow University of Health Sciences and Civil Hospital, Karachi, Pakistan. Tel: 0335-2577886, 0300-2269496; E-mail: qamaruddin99@gmail.com iological parameters are corrected after which the patient is shifted for definitive repair of injuries in the operating room. All packs are removed (if were previously placed) and bowel is carefully examined for any other injury that may have been missed. Any further bleeding is secured [5].

\section{INDICATIONS FOR DAMAGE CONTROL SURGERY}

Every trauma patient does not require damage control surgery. Many factors have been identified which may guide us to subject a patient to damage control laparotomy [2].

Various factors which affect the selection criteria for damage control management include

- The mechanism of injury

- Hypothermia (temperature $<35^{\circ} \mathrm{C}$ ),

- Severe metabolic acidosis (arterial $\mathrm{pH}<7.2$, base deficit $<15 \mathrm{mmol} / \mathrm{L}$ )

- Significant bleeding requiring massive transfusion (> 10 units $\mathrm{PRBC}$ )

- Operative time $>90 \mathrm{~min}$

- Coagulopathy (either on laboratory results or seen as 'non-surgical' bleeding) [2-6].

It is the responsibility of trauma surgeon to carefully decide the need for Damage control according to the condition of each patient. Overzealous application of damage control not only increases health cost in terms of theatre and ICU use 
but also increases the risk of intra-abdominal infection and abdominal wall hernias $[7,8]$.

\section{DAMAGE CONTROL RESUSCITATION}

Another important aspect of damage control surgery is the concept of damage control resuscitation. Previously, the focus of resuscitation was on rapid transfusion of intravenous fluids and maintaining mean blood pressure. But large volumes of intravenous fluids increase the blood pressure, reduces vasoconstriction resulting in more blood loss and is associated with clot disruption [9].

Damage control resuscitation helps improve outcome by focusing on four principle targets: [10].

1. Minimization of crystalloid

2. Permissive hypotension

3. Transfusion of a balanced ratio of blood products

4. Goal-directed correction of coagulopathy

Recent studies have favoured restricted fluid therapy and permissive hypotension as it maintains a mean blood pressure, decreases clot disruption and therefore, less bleeding [11]. Many studies have shown an improved outcome and reduction in mortality in patients with restricted fluid resuscitation than in patients who were given more intravenous fluid pre-operatively $[12,13]$. Mortality rates have been reported around $37 \%$ with traditional resuscitation as compared to $21 \%$ with restricted fluids [14].

\section{PRE-HOSPITAL PHASE}

It is the earliest phase of damage control which begins at the site of trauma and continues through the emergency room till the patient reaches the operating room safely. Early recognition of injury, damage control resuscitation and immediate transfer to operating room are key elements of this phase. Clear communication between the transporting and hospital team is important in mobilizing resources and saving precious time in the care of an already critical patient [11].

Initial fluid resuscitation is provided by two wide bore intravenous cannulas, samples for cross match are sent and fluid resuscitation is started with crystalloid solution which is replaced by blood products as soon as they are available. Aim is to maintain a systolic blood pressure of $90 \mathrm{~mm} \mathrm{Hg}[15$, 16]. Fresh frozen plasma and packed red cells are used in the ratio of $1: 1$ or 1:2 $[17,18]$. The early use of packed red cells and plasma expands volume, reverses coagulopathy and improves the oxygen carrying capacity of blood. No time should be wasted on unnecessary investigations.

\section{DAMAGE CONTROL PHASE}

This is carried out in operating room. Focus is on controlling haemorrhage as well as control of contamination from bowel injury while resuscitation continues. Stapling of bowel to limit contamination and use of abdominal packs to control haemorrhage may be employed. Definitive repair, reestablishing intestinal continuity and stoma formation are avoided at this time as this will increase the procedure time and also further derange the physiological parameters. The damage control Laparotomy should ideally be less than 90 minutes in duration [19].

The preferred incision is midline incision from xiphisternum to symphsis pubis. Visceral injuries are dealt individually. Bleeding raw surfaces like that of liver are most commonly treated by direct pressure or peri-hepatic packing [20, 21]. Peri-hepatic packing involves manual closure or approximation of the parenchyma, followed by the consecutive placing of dry abdominal packs around the liver and straight over the injury to provide tamponade to a bleeding site. Minimal number of dry laparotomy pads necessary to stop bleeding, should be applied to avoid compression of inferior vena cava. Pringles maneuver may be applied if bleeding doesn't stop. Simple lacerations of liver may be primarily repaired.

All other visceral injuries are managed according to the grade of injury [22, 23]. For major vascular injuries, damage control options are either vessel ligation or placement of temporary intravascular shunts. arteries [24, 25].

Pelvic fractures are treated by applying pelvic binders. If there is expanding haematoma and patient is unstable then preperitoneal pelvic packing can be done in which laparotomy pads are placed in preperitoneal space via a small suprapubic incision to stop bleeding [26].

Once bleeding is secured and bowel contamination controlled, then abdomen is temporarily closed. Different methods are used to close the abdomen like the use of towel clips, applying bogota bag, vacuum pack closure, direct closure with nylon and abdominal compartment syndrome is avoided. A good closure technique is inexpensive, protects the surrounding skin and viscera and lets the fluid to evacuate thereby, allowing easy closure without development of tension $[27,28]$. Commercially prepared vacuum negative pressure dressings (VAC abdominal dressing systems) are also available. They prompt primary closure and have fewer complications like enterocutaneous fistulas (reported between 1.2 - 15\%) [29]. Barker's vacuum packing technique can also be used for creating a vacuum dressing [11].

\section{ICU RESUSCITATION PHASE}

Once acute bleeding and spillage have been controlled, patient is shifted to ICU for resuscitation and optimization of physiology. Duration of resuscitation varies for each patient, ranging between 12 to $72 \mathrm{hrs}$. To date, there are no set criteria to label a patient as a survivor in ICU settings, but a decrease in raised serum lactate levels and correction of coagulopathy are important parameters [30]. 
Coagulation profile, hypovolemia and anaemia are corrected by transfusing blood products. As discussed previously, there is no set formula for transfusion but in case of massive haemorrhage, blood products are transfused in the ratio of 1:1:1 (PRBC:FFP:Platelets). It is associated with reduced mortality and reduced use of fluids. Crystalloid use is more limited [31, 32].

Re-warming of patients is done by using warmers, blankets and warmed fluids. It reduces mortality, improves coagulation cascade and reduces acidosis [30] .Despite all these measures, there is a subgroup of patients, who may require an earlier visit to the operating room. These are the ones who have an ongoing need for blood transfusion (despite having a normal clotting profile) where some bleeding source may have been missed or those who develop abdominal compartment syndrome. Such patients are shifted to operating room and the problem is addressed.

\section{DEFINITIVE REPAIR PHASE}

Before transitioning to this phase, the team should ensure that adequate resuscitation and physiological optimization has been achieved. Serum lactate levels are reduced, an adequate urine output established, clotting profiles corrected and end organ perfusion is maintained. This may take 24 to 72 hrs. Once in operating room, the abdominal packs are removed, if were placed previously. Bowel is rechecked for any missed injury and haemostasis is secured. There is literature available suggesting resection and anastomosis of injured bowel segment rather than formation of a stoma, however, ostomies may be preferred as patient's physiology may not support an anastomosis or if abdominal closure cannot be achieved [33].

Once the definitive repair has been done, the most important step is abdominal closure without fascial tension. High complication rates are associated with an open abdomen, most challenging of which is an enterocutaneuous fistula with mortality rates as high as $40 \%$ [34]. A standard fascial closure should be achieved without tension. However, if this cannot be achieved or a peak airway pressure $>10 \mathrm{~cm} \mathrm{H}_{2} \mathrm{O}$ during abdominal closure is encountered, then the suspicion of abdominal compartment syndrome should be raised and a temporary closing device should be applied to the abdomen. Usually, with the help of these measures, a permanent closure can be achieved within a week.

\section{COMPLICATIONS FROM DAMAGE CONTROL LA- PAROTOMY}

Damage control laparotomy may result in various complications including sepsis, intra-abdominal abscess, enterocutaneous fistulas, misuse of the concept of damage control itself and the development of abdominal compartment syndrome. We would like to discuss abdominal compartment syndrome as it is most feared in such patients due to aggressive resuscitation and third spacing.

\section{ABDOMINAL COMPARTMENT SYNDROME}

The normal intra-abdominal pressure is between 5 to $7 \mathrm{~mm}$ $\mathrm{Hg}$. Abdominal compartment syndrome (ACS) is defined as 'a sustained Intra Abdominal Pressure (IAP) > $20 \mathrm{mmHg}$. [35].

Abdominal compartment syndrome can be Primary, Secondary or Recurrent. Primary abdominal compartment syndrome deals with pathology in abdomen like abdominal trauma or haemoperitoneum, where an early surgical intervention might be needed. A secondary abdominal compartment syndrome results from pathologies arising from 'third spacing' and where the primary origin is not from abdomen like sepsis, burns and massive fluid resuscitation. Recurrent abdominal compartment syndrome refers to a condition in which ACS redevelops following previous surgical or medical treatment of primary or secondary ACS, for example, ongoing haemorrhage in a patient after damage control laparotomy.

Whatever the mechanism, the abdominal compartment syndrome leads to raised intra-abdominal and intra-thoracic pressures leading to decreased glomerular filtration rates, decreased urine output, decreased venous return, increased airway pressures, extremity and splanchnic ischaemia. The intra-abdominal pressure is measured simply by measuring urinary bladder pressure.

The prevalence of abdominal compartment syndrome in major trauma patients is approximately $30 \%$, with the mortality rate as high as $60 \%[36,37]$. Both supportive measures and decompression are used in management. The goals of supportive care in patients with intra-abdominal hypertension include reduction of intra-abdominal volume through evacuation of intraluminal contents, evacuation of intraabdominal space-occupying lesions (e.g., ascites, haematoma) when possible and measures to improve abdominal wall compliance for example the use of adequate analgesia, sedation and ventilator if required. Surgical decompression is a standard treatment in abdominal compartment syndrome [35, 36]. This is mostly performed at an intra-abdominal pressure $>25 \mathrm{~mm} \mathrm{Hg}$.

\section{CONCLUSION}

Damage control laparotomy and damage control resuscitation are aimed at restoring a normal physiology rather than a normal anatomy and are associated with an improved survival and prognosis. This requires coordinated team work which begins in the pre-hospital phase and continues in succession, till the last phase of definitive repair. Failure to recognize 
signs of coagulopathy and deterioration in a patient will increase the morbidity and mortality.

\section{CONFLICT OF INTEREST}

Declared none.

\section{ACKNOWLEDGEMENT}

Declared none.

\section{REFERENCES}

[1] Ball C. Damage control resuscitation: history, theory and technique. Can. J. Surg., 2014; 57(1): 55-60. DOI: 10.1503/cjs.020312

[2] Lamb C, MacGoey P, Navarro A, Brooks A. Damage control surgery in the era of damage control resuscitation. Br. J. Anaesth., 2014; 113(2): 242-249. DOI: 10.1093/bja/aeu233

[3] Rotondo M, Schwab C, McGonigal M, Phillips G, Fruchterman T, Kauder D, et al. Damage control: an approach for improved survival in exsanguinating penetrating abdominal injury. $J$. Trauma. 1993; 35(3): 375-383.

[4] Johnson J, Gracias V, Schwab C, Reilly P, Kauder D, Shapiro M, et al. Evolution in damage control for exsanguinating penetrating abdominal injury. J. Trauma., 2001; 51(2): 261-271.

[5] Scott-Conner C. Damage Control Laparotomy. Chassin's operative strategy in general surgery. $4^{\text {th }}$ ed. Newyork: Springer; 2014; 5557.

[6] Williams N, Bulstrode C, O'Connell P. Bailey love's short practice of surgery. $26^{\text {th }}$ ed. Boca Raton: Taylor and Francis; 2013.

[7] Miller R, Morris J., Diaz J, Herring M, May A. Complications after 344 damage-control open celiotomies. J. Trauma., 2005; 59(6): 1365-1374.

[8] Brenner M, Bochicchio G, Bochicchio K, Ilahi O, Rodriguez E, Henry S, et al. Long-term impact of damage control laparotomy: a prospective study. Arch. Surg., 2011; 146(4): 395-399. DOI: 10.1001/archsurg.2010.284

[9] Smith J, Pittet J, Pierce A. Hypotensive resuscitation. Curr. Anesthesiol. Rep., 2014; 4(3): 209-215. DOI: 10.1007/s40140-0140064-7

[10] Chang R, Holcomb J. Optimal fluid therapy for traumatic hemorrhagic shock. Crit. Care Clin., 2017; 33(1): 15-36. DOI: http://dx.doi.org/10.1016/j.ccc.2016.08.007

[11] Waibel B, Rotondo M. Damage control surgery: it's evolution over the last 20 years. Rev. Col. Bras. Cir., 2012; 39(4): 314-21. DOI: http://dx.doi.org/10.1590/S0100-69912012000400012

[12] Duke M, Guidry C, Guice J, Stuke L, Marr A, Hunt J, et al. Restrictive fluid resuscitation in combination with damage control resuscitation: time for adaptation. J. Trauma Acute Care Surg., 2012; 73(3): 674-8. DOI: 10.1097/TA.0b013e318265ce1f

[13] Ley E, Clond M, Srour M, Barnajian M, Mirocha J, Margulies D, et al. Emergency department crystalloid resuscitation of $1.5 \mathrm{~L}$ or more is associated with increased mortality in elderly and nonelderly trauma patients. J. Trauma., 2011; 70(2): 398-400. DOI: 10.1097/TA.0b013e318208f99b

[14] El Sayad M, Noureddine H. Recent advances of hemorrhage management in severe trauma. Emerg. Med. Int., 2014; 2014(2014): 638956. DOI: 10.1155/2014/638956

[15] Søreide E, Deakin C. Pre-hospital fluid therapy in the critically injured patient-a clinical update. Injury. 2005; 36(9): 1001-1010. DOI: http://dx.doi.org/10.1016/j.injury.2005.01.002
[16] Holcomb J, Jenkins D, Rhee P, Johannigman J, Mahoney P, Mehta $\mathrm{S}$, et al. Damage control resuscitation: directly addressing the early coagulopathy of trauma. J. Trauma Acute Care Surg., 2007; 62(2): 307-310. DOI: 10.1097/TA.0b013e3180324124

[17] Hirshberg A, Dugas M, Banez E, Scott B, Wall M, Mattox K Minimizing dilutional coagulopathy in exsanguinating hemorrhage: a computer simulation. J. Trauma Acute Care Surg., 2003; 54(3): 454-463. DOI: 10.1097/01.TA.0000053245.08642.1F

[18] Malone D, Hess J, Fingerhut A. Massive transfusion practices around the globe and a suggestion for a common massive transfusion protocol. J. Trauma Acute Care Surg., 2006; 60(6): S91-S6. DOI: 10.1097/01.ta.0000199549.80731.e6

[19] Hirshberg A, Sheffer N, Barnea O. Computer simulation of hypothermia during damage control laparotomy. World J. Surg., 1999; 23(9): 960-965.

[20] Ali U, Noor A, Shah M, Alam W. Trauma management in a tertiary care hospital in Peshawar, Pakistan. J. Ayub Med. Coll., Abbottabad., 2008; 20(3): 112-116.

[21] Saaiq M, Niaz-ud-Din, Zubair M, Shah S. Presentation and outcome of surgically managed liver trauma: experience at a tertiary care teaching hospital. interventions. J. Pak. Med. Assoc., 2013; 63(4): 436-439.

[22] Shoobridge J, Corcoran N, Martin K, Koukounaras J, Royce P, Bultitude M. Contemporary management of renal trauma. Rev. Urol., 2011; 13(2): 65-72.

[23] Mehta N, Babu S, Venugopal K. An experience with blunt abdominal trauma: evaluation, management and outcome. Clin. Pract., 2014; 4(2):599. DOI: 10.4081/cp.2014.599

[24] Granchi T, Schmittling Z, Vasquez J, Schreiber M, Wall M. Prolonged use of intraluminal arterial shunts without systemic anticoagulation. Am. J. Surg., 2000; 180(6): 493-497.

[25] Rasmussen T, Clouse W, Jenkins D, Peck M, Eliason J, Smith D. The use of temporary vascular shunts as a damage control adjunct in the management of wartime vascular injury. J. Trauma Acute Care Surg., 2006; 61(1): 8-15.

DOI: 10.1097/01.ta.0000220668.84405.17

[26] Glass N, Burlew C. Preperitoneal pelvic packing: how and when. Curr. Trauma Rep., 2015; 1(1): 1-7. DOI: 10.1007/s40719-0140001-8

[27] Barker D, Kaufman H, Smith L, Ciraulo D, Richart C, Burns R Vacuum pack technique of temporary abdominal closure: a 7-Year experience with 112 Patients. J. Trauma Acute Care Surg., 2000; 48(2): 201-207.

[28] Miller P, Meredith J, Johnson J, Chang M. Prospective evaluation of vacuum-assisted fascial closure after open abdomen: planned ventral hernia rate is substantially reduced. Ann. Surg., 2004; 239(5): 608-616

[29] Cheatham M, Demetriades D, Fabian T, Kaplan M, Miles W, Schreiber M, et al. Prospective study examining clinical outcomes associated with a negative pressure wound therapy system and barker's vacuum packing technique. World J. Surg., 2013; 37(9): 2018-2030. DOI: 10.1007/s00268-013-2080-Z

[30] Rossaint R, Bouillon B, Cerny V, Coats T, Duranteau J, FernándezMondéjar E, et al. The European guideline on management of major bleeding and coagulopathy following trauma. Crit. Care. 2016; 20(1): 1. DOI: 10.1186/s13054-016-1265-x

[31] Holcomb J, Wade C, Michalek J, Chisholm G, Zarzabal L, Schreiber M, et al. Increased plasma and platelet to red blood cell ratios improves outcome in 466 massively transfused civilian trauma patients. Ann. Surg., 2008; 248(3): 447-458.

[32] Lustenberger T, Frischknecht A, Brüesch M, Keel MJ. Blood component ratios in massively transfused, blunt trauma patients-a 
time-dependent covariate analysis. J. Trauma Acute Care Surg., 2011; 71(5): 1144-1151. DOI:10.1097/ta.0b013e318230e89b

[33] Anjaria D, Ullmann T, Lavery R, Livingston D. Management of colonic injuries in the setting of damage-control laparotomy: one shot to get it right. J. Trauma Acute Care Surg., 2014; 76(3): 594600. DOI: 10.1097/TA.0000000000000132

[34] D'Hondt M, Devriendt D, Van R, Vansteenkiste F, D'Hoore A, Penninckx F, et al. Treatment of small-bowel fistulae in the open abdomen with topical negative-pressure therapy. Am. J. Surg., 2011; 202(2): 20-24. DOI:10.1016/j.amjsurg.2010.06.025

[35] Kirkpatrick A, Roberts D, De Waele J, Jaeschke R, Malbrain M, De Keulenaer B, et al. Intra-abdominal hypertension and the abdominal compartment syndrome: updated consensus definitions and clinical practice guidelines from the world society of the abdominal compartment syndrome. Intensive Care Med., 2013; 39(7): 11901206. DOI:10.1007/s00134-013-2906-z

[36] Huang Y, Li Y. Open abdomen in trauma patients: a double-edged sword. Mil. Med. Res., 2016; 3:10. DOI: 10.1186/s40779-0160079-0

[37] Balogh Z, Lumsdaine W, Moore E, Moore F. Postinjury abdominal compartment syndrome: from recognition to prevention. Lancet. 2014; 384(9952): 1466-1475.

DOI:10.1016/s0140-6736(14)61689-5

(C) 2017 National journal of health sciences.

This is an open-access article. 